\title{
The Effect of Teaching Coping Skills on the Anxiety in Caregivers of Patients with Cancer Undergoing Chemo- Crossuark therapy
}

\author{
Mahnaz Seyedolshohadaee ${ }^{1}$, Parimehr Ayar ${ }^{1 *}$, Marjan Mardani ${ }^{2}$, Hamid Haghani ${ }^{3}$
}

1. Department of Internal Surgical, School of Nursing \& Midwifery, Iran University of Medical Sciences, Tehran, Iran.

2. Department of Psychiatric Nursing, School of Nursing \& Midwifery, Iran University of Medical Sciences, Tehran, Iran.

3. Department of Biological Statistics, School of Management and Medical Information, Iran University of Medical Sciences, Tehran, Iran.

citation: Seyedolshohadaee, M, Ayar, P, Mardani, M \& Haghani, H 2016, 'The effect of teaching coping skills on the anxiety of caregivers of patients with cancer undergoing chemotherapy', Journal of Client-Centered Nursing Care, vol. 2, no. 1, pp. 27-36. https://doi.org/10.32598/jccnc.2.1.27

: https://doi.org/10.32598/jecnc.2.1.27

Article info:

Received: 23 Aug. 2015

Accepted: 02 Dec. 2015
Keywords:

Anxiety, Cancer, Caregivers, Coping skills

\begin{abstract}
A B S T RA C T
Background: Long-term hospitalization for cancer treatment can prevent the continuation of a normal life of patients with cancer and their families. In this regard, caregivers face with problems such as psychological stress, hopelessness, fear, anxiety, and feelings of depression. The aim of this research was to investigate the effect of teaching of coping skills on the anxiety in caregivers of patients with cancer undergoing chemotherapy.

Methods: This research was a quasi-experimental study, pretest-posttest design with control group which started from October 2014 and lasted until February 2015. In this study, 62 caregivers of cancer patients were selected by convenience sampling method. A total of 30 subjects were non-randomly assigned in the experimental (intervention) group and 32 ones in the control group. The intervention was done based on a defined plan, which included teaching coping strategies to the experimental group in 4 sessions (45-60 minutes each session) using booklet and question and answer (QA) meeting. The control group received routine education. After 4 weeks, both groups were compared in terms of anxiety using Beck anxiety inventory questionnaire. The data were analyzed using SPSS 18 software, through performing paired t test, the Chi-square test, the Independent t-test, and Fisher's exact test.

Results: There was no significant difference regarding the anxiety between the experimental and control groups before the intervention $(\mathrm{P}=0.122)$. Four weeks after the intervention, anxiety of the experimental group improved, but no improvement was observed in the control group. Therefore, the two groups had statistically significant differences in this regard $(\mathrm{P}=0.001)$.

Conclusion: With regard to anxiety of the caregivers of the patients with cancer undergoing chemotherapy, the results showed the effectiveness of intervention i.e., teaching coping skills. Considering the effectiveness of teaching coping skills and consequently decreased anxiety in the caregivers of patients with cancer patients undergoing chemotherapy, it is suggested that this intervention be included in nurses family-centered care program.
\end{abstract}

\footnotetext{
* Corresponding Author:

Parimehr Ayar, MSc.

Address: Department of Medical-Surgical Nursing, School of Nursing \& Midwifery, Iran University of Medical Sciences, Tehran, Iran.

Tel: +98 (938) 2925436

E-mail: parimehrayar@gmail.com
} 


\section{Background}

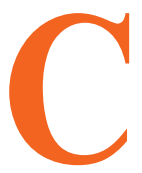

ancer as one of the biggest health problems (Baykal et al. 2009) affects all individuals regardless of race, gender, or social, economic, and cultural status. American Cancer Society has stated that cancer accounted for $9 \%$ of deaths worldwide (O'Hara et al. 2010; Siegel et al. 2012). However, chemotherapy is one of the important treatment methods in patients with cancer (O'Hara et al. 2010).

Because of the debilitating nature of the disease and its treatment, many people require help from informal caregivers, who help them with their daily activities. Because of the chronic nature of cancer, patients have to accept long-term treatments with chemotherapy drugs. Treatment lasts weeks or months and its side effects can be nausea, hair loss, fatigue, muscle aches, skin burns, weight changes, and psychological problems (Milbury et al. 2013; Seyed Fatemi et al. 2006). During the caring role of their favorite patients, caregivers regularly face with changes in patient's conditions and developing new situations, which also create changes in their lifestyle (Ferrans et al. 2005).

Meanwhile, the stress of care includes psychological, physical, and social distress imposed to caregivers as a result of caring patients with chronic diseases. Later on, caregivers will face with many problems such as burnout, depression, and anxiety (Abbasi et al. 2013). The burden of care that caregivers experience is different aspects of stress which is due to imbalance between care demand and the availability of resources to meet these demands (Salmani et al. 2014). In a study by Park et al. the prevalence of anxiety among caregivers of patients with cancer was reported to be $38.1 \%$. Of them, $20.3 \%$, $13.3 \%$, and $4.6 \%$ had mild, moderate, and severe anxiety, respectively (Park et al. 2013).

Caregivers face with problems such as psychological stress, despair, fear, anxiety, and feelings of depression. Anxiety is a condition characterized by feeling of fear accompanied by physical symptoms indicative of excessive activity of the autonomic nervous system which actually is a response to an unknown and ambiguous threat combined with conflict. Meanwhile, attention should be paid to the needs of family caregivers so that they can continue to take care of their own health and provide the best possible care for cancer patients (Porter et al. 2011).

Caregivers of patients with cancer experience various degrees of fatigue, anxiety, and burden of care. They have low quality of life and have to meet the needs of their own and patients at the same time. Therefore, health care providers must pay attention to caregivers in terms of fatigue, emotional stress, burden of care, and quality of life (Fotokian et al. 2004; Johansson et al. 2004). Also, older caregivers have more stressful relationships with the patients. Based on the reports, they have higher levels of anxiety with less social support (Ghaedi Grant et al. 2013).

However, any change in human life either pleasant or unpleasant requires a kind of readjustment (Momeni et al. 2013). Coping mechanisms can be considered a set of functions that are able to help the person tolerate, avoid, or minimize the effects of stress. Family caregivers can benefit from coping mechanisms to cast aside the caring anxiety. Researchers in this field believe that coping strategies can be considered as mental and behavioral efforts to manage the internal and external changes, because these changes create stress in the person and coping is a way to control the stress. Therefore, coping is an active and dynamic process, which should be altered constantly based on environmental changes (Gharraee et al. 2008)

To describe the results of the program, according to Demirbag et al. (2012) study, it is expected that training increases awareness of caregivers and decreases their anxiety (Demirbag 2012). The purpose of this study was to determine the effect of teaching coping skills on the anxiety of caregivers of patients with cancer undergoing chemotherapy.

\section{Materials \& Methods}

This research was a quasi-experimental study, pretestposttest design with a control group. In this study, the effect of teaching coping methods on the anxiety in caregivers of patients with cancer undergoing chemotherapy has been investigated. After receiving ethical approval of Iran University of Medical Sciences Ethics Committee and permission to conduct the study the researcher referred to the study setting (health centers of Iran University of Medical Sciences) according to a predetermined program.

After obtaining permission from the hospital authorities and the chemotherapy section and introduction to the research units, the researcher explained the study objectives and how the research was going to be conducted. Then, after taking written informed consents and based on the inclusion criteria, the study participants were selected with these criteria: being 18 years or older, passing at least 6 months from the patient's diagnosis, being patient's first degree family member, being able to speak, read, and write in Persian, no having any mental and physical disorders, also the cancer patients were in the first or second stage. 


\section{Participants}

Study sampling was done by convenience sampling method. To determine the sample size at $95 \%$ level of confidence, $80 \%$ power, and assuming that the effect size of teaching coping skills on the burden of care caregivers (compared with the control group) should be at least $5(d=5)$ to be considered statistically significant, the sample size in each group was calculated after inserting the proper amounts in the following formula:

$$
N=\left(\left(Z_{-}(1-\alpha / 2)+Z_{-}(1-\beta)\right)^{\wedge} 2 \times 2 S^{\wedge} 2\right) / d^{\wedge} 2
$$

Then, 30 participants were non-randomly assigned in the intervention group and 32 participants in the control group. However in the beginning of this research, 78 caregivers of patients suffering from various types of cancers (40 caregivers in experimental group and 38 ones in the control group) were selected. They referred to receive chemotherapy courses for their patients. During the training, due to the debilitating nature of the disease, its rapid progression, metastasis, and many concerns resulting from caring and everyday life, 10 caregivers left the research during training. The researcher compensated the loss with recruiting samples from above mentioned sections during 4 training sessions and continued that as far as the samples size reached to 30 trained caregivers. Also, during sample collection, 6 patients of the caregivers in the control group died due to illness and the size of the sample dropped to 32 people. The subjects in the sample were caregivers whose patients were receiving chemotherapy. They referred to research environment of Oncology for chemotherapy along with their patients in hospitals affiliated to Iran University of Medical Sciences, including Hazrat-eRasool and Firoozgar hospitals.

To prevent data leakage, the researcher randomly selected two centers for choosing intervention and control samples. Thus, the experimental group were selected from Hematology section 1 and 2 of Firoozgar Hospital and control group were selected from the Hematology and Oncology sections and clinic of Hazrat-e-Rasool Hospital. Based on the exclusion criteria those caregivers who did not attend one of the training sessions, whose patients' diseases spread (metastasis) or aggravated from stage 2 to higher (diagnosed by the physician), died, or changed treatment from chemotherapy to radiotherapy, were removed from the study.

\section{Intervention}

Both groups completed the study questionnaires before the intervention, then the control group received routine training, but the intervention group were divided into small groups (5 to 8 people in each group) and undergone train- ing on coping skills in 4 sessions of $45-60$ minutes long using booklet and questions and answer (QA) meetings. All sessions were held in the charity building (Guest House) of Firoozgar Hospital along with the refreshment. Sessions were held separately for each group and participants were informed in advance about the schedule and the time of the next session of classes and they were also contacted on the day of the session. At the end of each session, participants were asked to do assignments for the next session and necessary explanations were given about how and why to do the assignment. The content of the teaching booklet was prepared by the researcher and using existing resources and its validity and reliability were confirmed by $10 \mathrm{mem}$ bers of the faculty of Iran University of Medical Sciences.

Educational topics (booklet) were as follows. The first session: concept of the crisis, types of the crisis, voluntarily evaluation of the problems of the caregivers to have an overall idea; summary of the second session: reviewing the previous subjects, the concept of coping, coping types, inefficient coping, questions about the purposes and experiences according to the subjects taught for collaboration and evaluation; summary of the third session: reminding the past content and beginning to teach effective coping methods, questions about individuals' experiences to assess their performance in the past; summary of the fourth session: review of the previous session, teaching anxiety relaxation techniques and conclusion, summation of the topics, presentation of the report regarding previous assignments, questions about family experiences and the methods used at the time of anxiety, and questions and answers about the materials taught. After 4 weeks, questionnaires were completed again by both intervention and control groups.

\section{Data collection}

Following instruments were used in this study:

\section{Demographic data questionnaire}

This questionnaire consisted of two parts. Part 1 was dedicated to the information about caregiver and the second part to the information on the patient receiving chemotherapy (Table 1). Information about the caregiver comprised age, gender, education level, marital status, place of residence, occupation, economic status, field of study, occupation before being caregiver, income, history of caring, having another patient at home, insurance coverage. The patient's information (who was undergoing chemotherapy) included age, gender, education level, stage of cancer, type of cancer, and the number 
of chemotherapy sessions. The validity and reliability of this questionnaire were confirmed by 10 members of the faculty of Nursing and Midwifery of Iran University.

\section{Beck anxiety inventory (BAI)}

This questionnaire had 21 questions each of them scored on 4-point scale from 0 to 3 . Each of the test material describes one of the most common symptoms of anxiety (mental, physical, panic symptoms). In this regard, total scores from 0 to 21 indicate very mild symptoms of anxiety, 22 to 35 indicates moderate anxiety, and over 36 will show severe anxiety (Kazemi 2003) (Table 3).

In a survey by Pedram et al. (2010) entitled 'The effectiveness of cognitive-behavioral group therapy on the treatment of anxiety disorders, depression, and giving hope to women with breast cancer', Kazemi (2003), as cited in Beck (1988), the internal consistency of this scale was $93 \%$ and its test-retest reliability was $75 \%$. The reliability of this test in Iran calculated by the Cronbach $\alpha(n=34)$ has been reported as $78 \%$ (Friethriksdottir et al. 2011).

\section{Ethical consideration}

With regard to the observance of ethical principles in this study (registered with the code of ethics ir.iums. rec.1394.9211196250), the study participants were assured that any time they would not like to decline training sessions, they can leave and there would not be any interference in health care of their patients. Also, an educational booklet along with the introduction of publications of nutrition books about cancer was presented to all participants (the intervention and control groups).

\section{Statistical analysis}

Data were analyzed by performing paired t-test, the Independent t-test, the Chi-square test, and Fisher's exacttest, in SPSS version 21..

\section{Results}

The results showed that majority of caregivers in the experimental group (70\%) and in the control group (59.4\%) were female $(\mathrm{P}=0.382)$. Regarding job status, most caregivers were employed, $40 \%$ in the experimental group and $8.3 \%$ in the control group $(\mathrm{P}=0.565)$. The duration of disease and caring from patients and their caring by caregivers was about 6 to 10 months, which comprised $63.3 \%$ in the experimental group and $53.1 \%$ in the con- trol group and there was no significant difference between two groups in this regard $(\mathrm{P}=0.299)$. In terms of insurance coverage, $86.7 \%$ in the experimental group and $100 \%$ in the control group used insurance services which according to Fisher's exact test, there was no significant difference between them $(\mathrm{P}=0.049)$ (Table 1).

The mean(SD) of anxiety scores in caregivers of patients with cancer undergoing chemotherapy in the experimental group were 18.60(12.57) and 23.56(12.31) in the control group before the intervention, which changed to $12.07(8.94)$ in the experimental group and $27.47(11.50)$ in the control group after the intervention. In terms of comparing anxiety before the intervention, the experimental and control groups had no significant difference, although control group showed higher anxiety $(\mathrm{P}=0.122)$. Comparison of anxiety in both groups, 4 weeks after the intervention showed statistically significant difference $(\mathrm{P}=0.001)$ (Table 2).

Changes in subscales of caring anxiety in the experimental group showed that after the intervention the means of all 3 subscales decreased but in the control group the means of caring anxiety increased (Tables 3 and 4). The results in Table 5 indicate that according to P-value of the Independent t-test, changes in the two study groups with regard to caring anxiety had statistically significant differences $(\mathrm{P}<0.001)$. The mean of changes for caring anxiety in the experimental group decreased after the intervention but the mean for burden of care increased in the control group. Considering the statistical results, changes in caring anxiety subscales showed statistically significant differences between two groups. Assessment of changes in caring anxiety subscales in the experimental group showed that the means of all 3 subscales in this group decreased after the intervention, but in the control group this change was uprising and the mean of caring anxiety scores increased (Table 6).

\section{Discussion}

Our findings indicated that teaching coping skills reduced anxiety in caregivers of patients with cancer. In Chien et al. study with the aim of investigating the effect of need-based training program on the level of anxiety in caregivers in the intensive care unit it was showed that anxiety level in the family of intervention group decreased compared to the control group which reflects the effectiveness of this training. This finding is consistent with the results of the current study (Chien et al. 2006). Although this study has been conducted in another ward of the hospital and on different patients of the current study, it demonstrates the effectiveness of need-based training on 
Table 1. Demographic characteristics of the study subjects in experimental and control groups of caregivers of the patients undergoing chemotherapy.

\begin{tabular}{|c|c|c|c|c|c|}
\hline & Chomato & atios & Experimental group $(n=30)$ & Control group $(n=32)$ & D valu \\
\hline & & & No.(\%) & No.(\%) & \\
\hline & & Wife & $9(30)$ & $10(31.3)$ & \\
\hline & & Parents & $3(10)$ & $4(12.5)$ & \\
\hline & $\begin{array}{l}\text { Relationship with } \\
\text { the patient }\end{array}$ & Siblings & $3(10)$ & $3(9.4)$ & $<0.99$ \\
\hline & & Son/daughter & $15(50)$ & $15(46.9)$ & \\
\hline & & Total & $30(100)$ & $32(100)$ & \\
\hline & & $\leq 30$ & $8(26.7)$ & $10(31.3)$ & \\
\hline & & $31-40$ & $13(43.3)$ & $11(34.3)$ & \\
\hline & Age, $y$ & $41-50$ & $6(20)$ & $5(15.6)$ & 0.369 \\
\hline & & $\geq 51$ & $3(10)$ & $6(18.8)$ & \\
\hline & & Total & $30(100)$ & $32(100)$ & \\
\hline Caregivers & & Single & $11(36.7)$ & $9(28.2)$ & \\
\hline & & Married & $16(53.3)$ & $23(71.8)$ & \\
\hline & & Divorced & $3(10)$ & $0(0.0)$ & \\
\hline & & Total & $30(100)$ & $32(100)$ & \\
\hline & & Employed & $12(40)$ & $14(43.8)$ & \\
\hline & Employment & Housewife & $11(36.7)$ & $14(43.8)$ & \\
\hline & status & Student and unemployed & $7(23.3)$ & $4(12.5)$ & 0.565 \\
\hline & & Total & $30(100)$ & $32(100)$ & \\
\hline & & Yes & $26(86.7)$ & $32(100)$ & \\
\hline & $\begin{array}{l}\text { Insurance cover- } \\
\text { age }\end{array}$ & No & $4(13.3)$ & $0(0)$ & 0.049 \\
\hline & & Total & $30(100)$ & $32(100)$ & \\
\hline & & $\leq 5$ & $1(3.3)$ & 1 (3.1) & \\
\hline & & $6-10$ & $19(63.3)$ & $17(53.1)$ & \\
\hline & $\begin{array}{l}\text { Duration of the } \\
\text { disease, month }\end{array}$ & $11-15$ & $6(20)$ & $6(18.8)$ & 0.299 \\
\hline & & $\geq 16$ & $4(13.3)$ & 8 & \\
\hline $\begin{array}{l}\text { Cancer } \\
\text { patients }\end{array}$ & & Total & 30 (100) & $32(100)$ & \\
\hline chemo- & & $\leq 5$ & $16(53.3)$ & $16(50)$ & \\
\hline & & $6-10$ & $10(33.3)$ & 7 (21.9) & \\
\hline & $\begin{array}{l}\text { Duration of } \\
\text { chemotherapy, }\end{array}$ & $11-15$ & $2(6.7)$ & $6(18.8)$ & 0.356 \\
\hline & & $\geq 16$ & $2(6.7)$ & $3(9.4)$ & \\
\hline & & Total & $30(100)$ & $32(100)$ & \\
\hline
\end{tabular}


Table 2. Numerical caring anxiety in caregivers for anxiety before the intervention in the experimental and control groups.

\begin{tabular}{|c|c|c|c|}
\hline & Group & Experimental group & Control group \\
\hline $\begin{array}{l}\text { Caring } \\
\text { anxiety }\end{array}$ & & No.(\%) & No.(\%) \\
\hline Mild & & $17(56.7)$ & $14(43.8)$ \\
\hline Moderate & & $10(33.3)$ & $11(34.4)$ \\
\hline Severe & & $3(10.0)$ & $7(21.9)$ \\
\hline Total & & $30(100.0)$ & $32(100.0)$ \\
\hline Mean $\pm S D$ & & $18.60 \pm 12.57$ & $23.56 \pm 12.31$ \\
\hline Independent t-test result & & $\mathrm{df}=60$ & $P$-value $=0.122$ \\
\hline
\end{tabular}

Client-Centered Nursing Care

Table 3. Numerical caring index of caregivers for anxiety after the intervention (4 weeks later) in the experimental and control groups.

\begin{tabular}{|c|c|c|c|}
\hline Group & Experimental group & & Control group \\
\hline anxiety & No.(\%) & & No.(\%) \\
\hline Mild & $26(86.7)$ & & $10(31.3)$ \\
\hline Moderate & $4(13.3)$ & & $13(40.6)$ \\
\hline Severe & $0(0.0)$ & & $9(28.1)$ \\
\hline Total & $30(100.0)$ & & $32(100.0)$ \\
\hline Mean $\pm S D$ & $12.7 \pm 8.94$ & & $27.47 \pm 11.50$ \\
\hline Independent t-test result & $\mathrm{df}=60$ & $t=-5.861$ & P-value $=<0.001$ \\
\hline
\end{tabular}

the anxiety of families and caregivers of patients. Reducing anxiety level in caregivers of patients with cancer undergoing chemotherapy, although statistically significant based on studies, needs effective training on longer time schedules since the anxiety (though with lower degrees) still exists.

In a study by Sadeghi et al. which investigated the effect of involving the patient's families on their anxiety levels, the results showed that the average severity of anxiety in participants was in very severe situation in the control group and moderate in the experimental group after the intervention. Comparing anxiety scores in experimental and control groups before and after the intervention showed that the average anxiety scores decreased after the intervention in the experimental group. In other words, involving family members in daily care of their patients reduces effectively the anxiety of the subjects which reflects the effectiveness of the intervention, in general, on the anxiety of the family (Sadeghi et al. 2013).
The results of the study by Ghaedi Heidari et al. also showed that combination of family psychoeducational interventions with common mental health care had considerable effect on reducing mental health problems of family caregivers. Based on their study, the family education program could be effective in reducing mental health problems (depression, anxiety, and stress) of family caregivers of patients with dementia (Ghaedi Heidari et al. 2014) that like the current study demonstrated the effectiveness of teaching in the context of behavioral change and as a result, improvement of psychological symptoms.

Another study had shown that average scores of depression, anxiety, and stress in the experimental group significantly has been reduced compared to the scores of the control group in the caregivers of patients with schizophrenia and mood disorders (Sadeghi et al. 2013). Furthermore, the family education program to reduce depression, anxiety, and stress has been effective in caregivers of mental patients and it has potentially improved and enhanced the quality of lives of patients and caregivers. Like the current study, the evidence supports the positive 
Table 4. Comparison of anxiety in caregivers of patients undergoing chemotherapy before and after the intervention in the experimental and control groups.

\begin{tabular}{|c|c|c|c|c|c|c|c|}
\hline \multicolumn{2}{|c|}{ Anxiety } & \multirow[t]{2}{*}{$\begin{array}{l}\text { Measurement } \\
\text { stage }\end{array}$} & \multicolumn{2}{|c|}{ Experimental group $(n=30)$} & \multicolumn{2}{|c|}{ Control group ( $n=32$ ) } & \multirow{2}{*}{ P-value } \\
\hline & & & Mean & SD & Mean & SD & \\
\hline \multirow{9}{*}{ Subscales } & \multirow{3}{*}{$\begin{array}{l}\text { Anxious } \\
\text { mood }\end{array}$} & $\begin{array}{l}\text { Before the inter- } \\
\text { vention }\end{array}$ & 2.33 & 1.90 & 2.75 & 2.54 & 0.466 \\
\hline & & $\begin{array}{c}\text { After the interven- } \\
\text { tion }\end{array}$ & 1.83 & 1.72 & 3.12 & 2.60 & 0.024 \\
\hline & & Difference & -0.50 & -1.33 & 0.37 & 1.72 & 0.029 \\
\hline & \multirow{3}{*}{$\begin{array}{l}\text { Specific } \\
\text { phobia }\end{array}$} & $\begin{array}{l}\text { Before the inter- } \\
\text { vention }\end{array}$ & 3.90 & 2.69 & 5.06 & 2.37 & 0.076 \\
\hline & & $\begin{array}{l}\text { After the interven- } \\
\text { tion }\end{array}$ & 2.90 & 2.40 & 6.28 & 1.89 & $<0.001$ \\
\hline & & Difference & -1.00 & 0.29 & 1.22 & 1.88 & $<0.001$ \\
\hline & \multirow{3}{*}{$\begin{array}{l}\text { Auto signs of } \\
\text { hyperactivity } \\
\text { and anxiety } \\
\text { motor stress }\end{array}$} & $\begin{array}{l}\text { Before the inter- } \\
\text { vention }\end{array}$ & 12.37 & 9.54 & 15.75 & 9.77 & 0.173 \\
\hline & & $\begin{array}{c}\text { After the interven- } \\
\text { tion }\end{array}$ & 7.33 & 6.44 & 18.06 & 8.93 & $<0.001$ \\
\hline & & Difference & -5.03 & -4.03 & 2.31 & 4.04 & $<0.001$ \\
\hline \multirow{3}{*}{$\begin{array}{l}\text { General } \\
\text { anxiety }\end{array}$} & \multirow{3}{*}{$\begin{array}{l}\text { General } \\
\text { anxiety }\end{array}$} & $\begin{array}{l}\text { Before the inter- } \\
\text { vention }\end{array}$ & 18.60 & 12.57 & 23.56 & 12.31 & 0.122 \\
\hline & & $\begin{array}{c}\text { After the interven- } \\
\text { tion }\end{array}$ & 12.07 & 8.94 & 27.47 & 11.50 & $<0.001$ \\
\hline & & Difference & -6.53 & -5.07 & 3.90 & 5.02 & $<0.001$ \\
\hline
\end{tabular}

Table 5. Numerical caring index in caregivers in experimental and control groups.

\begin{tabular}{|c|c|c|c|}
\hline \multirow{2}{*}{ Intervention group } & Experimental & Control & \multirow{2}{*}{ Independent t-test results } \\
\hline & Mean $\pm S D$ & Mean \pm SD & \\
\hline Pre & $60.57 \pm 18.12$ & $56.31 \pm 23.12$ & $\begin{array}{c}t=-1.570 \\
d f=60 \\
\text { P-value }=0.122\end{array}$ \\
\hline $\begin{array}{c}\text { Post } \\
\text { (4 weeks after the intervention) }\end{array}$ & $12.8 \pm 07.94$ & $47.50 \pm 27.11$ & $\begin{array}{c}t=-5.861 \\
d f=60 \\
\text { P-value }<0.001\end{array}$ \\
\hline Difference & $53.07 \pm-6.5$ & $90.02 \pm 3.5$ & $\begin{array}{c}t=8.132 \\
d f=60 \\
\text { P-value }<0.001\end{array}$ \\
\hline
\end{tabular}

impact of education on reducing anxiety. Also, in the present study, although comparing the mean scores of anxiety in caregivers of cancer patients undergoing chemotherapy before and after the intervention in the experimental and control groups showed the reduction of anxiety in their caregivers, which was statistically significant, this anxiety still exists (though in lower degrees) and demonstrates the need for effective training on longer time schedules.

Regarding anxiety in caregivers of patients with cancer undergoing chemotherapy, identifying variables associ- ated with anxiety in caregivers could help optimize caresupport services and determine the effective solutions for variables involved in anxiety and depression at the specific time. Therefore, it is suggested that studies be conducted with larger samples in different medical centers with various socio-economic levels.

Designing projects based on spirituality, and with regard to the religious community of Iran have applications in solving problems and developing consistency. To examine the spectrum of caregivers' and their needs and problems 
and ways to provide information to patients' families, designing field studies can be beneficial. Furthermore, providing educational programs and studying psychological care of caregivers and seeking expert consultation are recommended for patients and their caregivers. Considering the study limitations and results, it is suggested that the effect of more comprehensive training programs, including psychotherapy approaches like mental imagery be investigated on anxiety and stress in care of caregivers. Also, with regard to the transferability of anxiety of caregivers to their patients, the mentioned psychological indicators be simultaneously investigated in the patients.

\section{Acknowledgements}

This article is extracted from MSc thesis of Nursing of the corresponding author submitted to Iran University of Medical Sciences. The authors express their gratitude to Research Deputy of the University and all the employees of affiliated hospitals, including Hazrat-e-Rasool (PBUH) and Firouzgar who provided the necessary cooperation. We are also grateful to all patients with cancer and their caregivers who assisted the researcher.

\section{Conflict of Interest}

The authors declared no conflict of interests

\section{References}

Abbasi, A, Shamsizadeh, M, Asayesh, H, Rahmani, H, Hoseini, SA \& Talebi, M 2013, 'The relationship between caregiver burden with coping strategies in Family caregivers of cancer patients, International Journal of Palliative Nursing, vol. 1, no. 3, pp. $62-71$

Baykal, U, Seren, S \& Sokmen, SA 2009, 'Description of oncology nurses' working conditions in Turkey', European Journal of Oncology Nursing, vol. 13, no. 5, pp. 368-75. doi: 10.1016/j. ejon.2009.04.004

Beck, AT, Epstein, N, Brown, G \& Steer, RA 1988, 'An inventory for measuring clinical anxiety: psychometric properties', Journal of Consulting and Clinical Psychology, vol. 56, no. 6, pp. 893-97. doi: 10.1037/0022-006x.56.6.893

Chien, WT, Chiu, YL, Lam, LW \& Ip, WY 2006, 'Effects of a needs-based education programme for family carers with a relative in an intensive care unit: a quasi-experimental study', International Journal of Nursing Studies, vol. 43, no. 1, pp. 39-50. doi: 10.1016/j.ijnurstu.2005.01.006

Demirbag, BC 2012, 'Impact of home education on levels of perceived social support for caregivers of cancer patients', Asian Pacific Journal of Cancer Prevention, vol. 13, no. 6, pp. 2453-458. doi: 10.7314/apjcp.2012.13.6.2458

Ferrans, CE, Zerwic, JJ, Wilbur, JE \& Larson, JL 2005, ‘Conceptual model of health-related quality of life, Journal of Nursing Scholarship, vol. 37, no. 4, pp. 336-42. doi: 10.1111/j.15475069.2005.00058.x
Fotokian, Z, Alikhani, M, Salman Yazdi, N \& Jamshidi, R 2004 '[Quality of lives of primary relatives providing care for their cancer patients (Persian)]', Iran Journal of Nursing, vol. 17, no. 38 , pp. $42-50$.

Friethriksdottir, N, Saevarsdottir, T, Halfdanardottir, SI, Jonsdottir, A, Magnusdottir, H, Olafsdottir, KL et al. 2011, ‘Family members of cancer patients: needs, quality of life and symptoms of anxiety and depression, Acta Oncologica, vol. 50, no. 2, pp. 252-58. doi: 10.3109/0284186x.2010.529821

Ghaedi Grant, M, Sun, V, Fujinami, R, Sidhu, R, Otis-Green, S, Juarez, G et al. 2013, 'Family caregiver burden, skills preparedness, and quality of life in non-small cell lung cancer', Oncology Nursing Forum, vol. 40, no. 4, pp. 337-46. doi: 10.1188/13. onf.337-346

Ghaedi Heidari, F, Pahlavanzadeh, S, Maghsoudi, J \& Ghazavi, Z 2014, '[Effect of family education program on depression, anxiety and stress of family caregivers of elderly individuals with dementia (Persian)]', Journal of Nursing Education, vol. 3, no. 1, pp. 12-20.

Gharraee, B, Mohammadi, SD \& Asgharnejad, AA 2008, '[The relationship of behavioral disorders and coping styles and strategies in secondary school students (Persian)]', Iraninan Psychiatry and Clinical Psychology, vol. 14, no. 1, pp. 39-46.

Johansson, I, Fridlund, B \& Hildingh, C 2004, 'Coping strategies of relatives when an adult next-of-kin is recovering at home following critical illness', Intensive \& Critical Care Nursing, vol. 20, no. 5, pp. 281-91. doi: 10.1016/j.iccn.2004.06.007

Kazemi, H 2003, '[A comparison of cognitive distortions in anxious and depressed (Persian)]', MA thesis, Shiraz University.

Lambert, SD, Girgis, A, Lecathelinais, C \& Stacey, F 2013, 'Walking a mile in their shoes: anxiety and depression among caregivers of cancer survivors at six and 12 months post-diagnosis. Support Care Cancer, vol. 21, no. 1, pp. 75-85. doi: 10.1007/ s00520-012-1495-7

Lkhoyaali, S, El Haj, MA, El Omrani, F, Layachi, M, Ismaili, N, Mrabti, H, et al. 2015, 'The burden among family caregivers of elderly cancer patients: prospective study in a Moroccan population', BMC Res Notes, vol. 8, pp. 347. doi: 10.1186/ s13104-015-1307-5

Milbury, K, Badr, H, Fossella, F, Pisters, KM \& Carmack, CL 2013, 'Longitudinal associations between caregiver burden and patient and spouse distress in couples coping with lung cancer. Support Care Cancer, vol. 21, no. 9, pp. 2371-379. doi: 10.1007/s00520-013-1795-6

Momeni, K, Karami, J \& Rad, AS 2013, ‘[The relationship between spirituality, resiliency and coping strategies with students' psychological well-being in Razi University of Kermanshah (Persian)]', Journal of Kermanshah University of Medical Sciences, vol. 16, no. 8, pp. 626-34.

Navidian, A, Salar, A, Hasheminia, A \& Keikhaei, A 2001, '[Study of mental exhaustion experienced by family caregivers of patients with mental disorders, Zahedan psychiatric hospital, 2000 (Persian)]', Journal of Babol University of Medical Sciences, vol. 3, no. 4, pp. 33-38.

O'Hara, RE, Hull, JG, Lyons, KD, Bakitas, M, Hegel, MT, Li, Z et al. 2010, 'Impact on caregiver burden of a patient-focused palliative care intervention for patients with advanced cancer', Palliative \& Supportive Care, vol. 8, no. 4, pp. 395-404. doi: $10.1017 / \mathrm{s} 1478951510000258$ 
Park, B, Kim, SY, Shin, JY, Sanson-Fisher, RW, Shin, DW, Cho, J et al. 2013, 'Prevalence and predictors of anxiety and depression among family caregivers of cancer patients: a nationwide survey of patient-family caregiver dyads in Korea', Support Care Cancer, vol. 21, no. 10, pp. 2799-807. doi: 10.1007/s00520013-1852-1

Pedram, M, Mohmaei, M, Naziri, GH \& Aeen Parast, N 2010, '[The effectiveness of cognitive - behavioral treatment of anxiety, depression and creat hope for women with breast cancer (Persian)]', Quarterly Sociology of Women, vol. 1, no. 4, pp. 61-75.

Porter, LS, Keefe, FJ, Garst, J, Baucom, DH, McBride, CM, McKee, DC et al. 2011, 'Caregiver-assisted coping skills training for lung cancer: results of a randomized clinical trial', Journal of Pain and Symptom Management, vol. 41, no. 1, pp. 1-13. doi: 10.1016/j.jpainsymman.2010.04.014

Sadeghi, Z, Payami, M \& Moosavinasab, SN 2013, '[Effect of family participation in icu patients care on family's anxiety level (Persian)]', Preventive Care in Nursing \& Midwifery Journal, vol. 2, no. 2, pp. 10-17.

Salmani, N, Ashketorab, T \& Hasanvand, SH 2014, ‘[Care and caregivers pressure is related factors in Yazd Hospital Oncology unit Shahvali (Persian)]', Journal of Shahid Beheshti School of Nursing \& Midwifery, vol. 23, no. 84, pp. 11-17.

Seyed Fatemi, N, Rezaei, M, Givari, A \& Hosseini F 2006, '[Prayer and spiritual well-being in cancer patients (Persian)]', Payesh Publication, Tehran.

Siegel, R, Naishadham, D \& Jemal, A 2012, 'Cancer statistics', CA: A Cancer Journal for Clinicians, vol. 62, no. 1, pp. 10-29. doi: 10.3322/caac. 20138 
